\title{
The Inclusion of Women in Studies of Occupational Cancer: A Review of the Epidemiologic Literature From 1991-2009
}

\author{
Hohenadel K., Raj P., Demers P.A., Zahm, S.H., and Blair A.
}

Version Post-Print/Accepted Manuscript

Citation Hohenadel K, Raj P, Demers PA, Zahm, SH, Blair A. The inclusion of

(published version) women in studies of occupational cancer: A review of the epidemiologic literature from 1991-2009. American Journal of Industrial Medicine 2015;58(3):276-281. PubMed ID 25678456.

Publisher's Statement This is the peer reviewed version of the following article: Hohenadel K, Raj P, Demers PA, Zahm, SH, Blair A. The inclusion of women in studies of occupational cancer: A review of the epidemiologic literature from 1991-2009. American Journal of Industrial Medicine 2015;58(3):276-281, which has been published in final form at https://dx.doi.org/ 10.1002/ajim.22424. This article may be used for non-commercial purposes in accordance with Wiley Terms and Conditions for Self-Archiving.

\section{How to cite TSpace items}

Always cite the published version, so the author(s) will receive recognition through services that track citation counts, e.g. Scopus. If you need to cite the page number of the TSpace version (original manuscript or accepted manuscript) because you cannot access the published version, then cite the TSpace version in addition to the published version using the permanent URI (handle) found on the record page. 


\section{ABSTRACT}

Introduction: Since the early 1990s, researchers have been concerned with the low rate at which women are included in epidemiologic studies of occupational cancer. A previous evaluation determined that one-third of articles published between 1970 and 1990 included women. Methods: To assess whether there has been an improvement in recent years, papers on occupational cancer between 1991 and 2009 were reviewed in fifteen journals.

Results: The proportion of articles that included men remained stable around $90 \%$, while proportion of articles that included women increased substantially, from 39\% in 1991-1995 to $62 \%$ in 2006-2009. Articles that assessed risk among men only or men and women presented a higher mean number of risk estimates and were more likely to evaluate dose-response relationships than studies including women.

Conclusions: Despite advances in the inclusion of women in studies of occupational cancer, disparities remain in the number of studies of occupational cancer and depth of analysis in studies that included women.

KEY WORDS: workplace, occupations, neoplasms, women's health 


\section{INTRODUCTION}

Since the early 1990s, researchers have been concerned with the low rate at which women are included in epidemiologic studies of occupational cancer (Blair et al. 1999; Gunnarsdottir et al. 1999; Niedhammer et al. 2000; Zahm et al. 1994; Zahm and Blair 2003). The lack of data on women is of concern given the increased number of women in the workforce, which has increased in the United States from 44\% in 1972 to 58\% in 2012 (United States Department of Labor, 2014); the higher proportion of women holding jobs with potentially hazardous exposures; and the reliance on data to determine risk of occupational cancer risk that predominantly comes from white men in previous decades (Blair et al. 1999; Friesen et al. 2013; Niedhammer et al. 2000; Pottern et al. 1994; Zahm and Fraumeni 1995; Zahm and Blair 2003).

Studies that evaluate the risk of cancer related to an occupation, industry, or workplace exposure among men are often ineffective in determining the risk to women for several reasons. First, and most obviously, studies of occupational cancer in men cannot evaluate female gynecologic cancers (Blair et al. 1999). Second, studies of occupational cancer in men are unable to account for sex (i.e., biological) and gender (i.e., contextual) differences in exposure patterns and susceptibility including factors related to their physical environments, absorption rate, and the amount of exposure that reaches the target site (Arbuckle 2006; Blair et al. 1999; Friesen et al. 2012). Third, studies of occupational cancer among men cannot account for differences in job tasks between men and women, which can occur even when job titles are the same (Kennedy and Koehoorn 2003; Locke et al., 2014).

Studies of occupational cancer that specifically evaluate risk for women are clearly warranted (Kennedy and Koehoorn 2003; Kogevinas and Zahm 2003; Messing et al. 2003; Messing and Mergler 2006; Zahm and Fraumeni 1995; Zahm and Blair 2003). In some cases, methodological adjustments need to be made, such as, when possible, increasing the sample sizes due to the generally smaller numbers of exposed women, utilizing gender-specific exposure assessment techniques, and considering sex- and gender-specific confounders related to reproductive and lifestyle factors (Arbuckle 2006; Kennedy and Koehoorn 2003; Blair et al. 1999). 
In 1994, Zahm and colleagues published a review that quantified the inclusion of women and minorities in epidemiologic studies of occupational cancer (Zahm et al. 1994). Their review of eight journals from 1971-1990 found that 35\% of articles included analyses examining white women and $10 \%$ of studies included analyses examining non-white women. Similarly, in 2000 , Niedhammer and colleagues reviewed articles published in 1997 in six journals and found that $31 \%$ of articles that assessed occupational health broadly included men and women and $7 \%$ included women only (Niedhammer et al. 2000). In the same decade, several international conferences took place and dedicated journal issues were published to highlight methodological barriers and promote the inclusion of women in epidemiologic studies of occupational cancer (Gunnarsdottir et al. 1999; Kogevinas and Zahm 2003; Pottern et al. 1994).

This review was undertaken to determine whether the proportion of articles assessing cancer risk among women associated with an occupation, industry, or workplace exposure have increased since Zahm and colleagues' review was completed in 1990, and to characterize studies that include women in terms of the number of risk estimates presented (i.e., the number of odds ratios or other measures), the presence of dose-response analyses, and the types of cancers and occupations analyzed. The eight journals assessed by Zahm and colleagues were reviewed from 1991-2009, along with an additional seven journals that frequently publish epidemiological articles on occupational cancer. 


\section{MATERIALS AND METHODS}

\section{Journals}

All issues and supplements were reviewed for the following fifteen journals from 1991-2009:

American Journal of Epidemiology; American Journal of Industrial Medicine; Annals of Epidemiology; Annals of Occupational Hygiene; Archives of Environmental Health; British Journal of Industrial Medicine/Occupational and Environmental Medicine; Cancer Causes and Control; Environmental Health Perspectives; Epidemiology; International Journal of Environmental and Occupational Health; International Journal of Epidemiology; Journal of Occupational and Environmental Hygiene; Journal of Occupational Medicine; Journal of the National Cancer Institute; Scandinavian Journal of Work, Environment and Health. Although information from each journal was abstracted by a single reviewer, standardized training was provided for each reviewer and periodic checks were completed to ensure that information was being obtained in a standardized manner.

\section{Inclusion criteria}

Articles were included in the review if they reported original risk estimates for an association between a cancer and an occupation, industry, or a workplace exposure. Systematic reviews, meta-analyses, and exposure assessment studies were excluded. Articles were also excluded if it was not possible to determine the gender composition of the study population.

\section{Gender}

An article was classified as including men, women or both based on the presence of risk estimates reported for those groups in the paper. Articles that excluded a gender group following the presentation of descriptive statistics were not considered to include that group. Counts were produced separately for articles that included:

1. Any men (i.e., men only or men and women)

2. Men only

3. Any women (i.e. women only or women and men)

4. Women only

5. Both men and women 
These five gender categories were included to allow for comparisons of counts of articles where men or women were the sole focus of the paper (i.e., the study was specifically designed to evaluate risk among either men or women) and articles where men and women are included but are not necessarily the sole focus of the paper (i.e., gender was not explicitly part of the inclusion or exclusion criteria). Due to this categorization method, there is some overlap: the "any men" category includes all studies in the "men only" category plus the studies that include both "men and women." Similarly, the "any women" category includes all studies in the "women only" category plus the studies that include both "men and women."

\section{Occupations and cancers}

Cancers were categorized according to the International Classification of Disease (ICD-9).

Occupations were classified according to the 2010 Standard Occupational Classification (United States Bureau of Labor Statistics, 2010).

\section{Risk estimates and dose-response analyses}

The number of risk estimates and the presence of dose-response analyses were determined for each article to serve as proxies for the depth of analyses performed. It was assumed that a greater number of risk estimates or the presence of dose-response, as opposed to simple binary, analyses signified greater depth.

\section{Analyses}

Data were entered into a Microsoft Access database and analyzed using SAS 9.2 (SAS Institute Inc. 2011). 


\section{RESULTS}

In total, 1,457 articles assessing cancer risk in relation to an occupation, industry, or workplace exposure were published in 15 journals from 1991-2009. Two articles were removed from further consideration because the gender composition of the study sample could not be determined, leaving 1,455 articles for analysis. The greatest numbers of articles were published between 1991-1995 and 1996-2000; there was a decline in the number of articles published in the two subsequent time periods (Table I). Across the entire study period, $91 \%$ of articles assessed the risk of occupational cancer among men and 50\% among women. Among the 1,455 papers, 41\% assessed risk among both men and women, 50\% among men only, and 9\% among women only.

Over time, the proportion of articles that assessed the risk of occupational cancer among men remained stable, while the proportion of articles that assessed cancer risk among men only declined in each time period from $61 \%$ in $1991-1995$ to $38 \%$ in $2006-2009$ (Figure 1). The proportion of articles that assessed the risk of occupational cancer among women increased substantially, from $39 \%$ in $1991-1995$ to $62 \%$ in $2006-2009$. The proportion of articles that assessed cancer risk among women only was unstable over the time periods, likely because of the small number of publications. The proportion of articles that assessed both men and women increased from $31 \%$ in $1991-1995$ to $50 \%$ in $2006-2009$.

\section{Risk estimates and dose-response analyses}

Articles that assessed the risk of occupational cancer among both men and women reported a higher mean number of risk estimates (e.g., odds ratios) (mean=117.0) than articles that assessed cancer risk among men only (mean=96.2). Articles on women only had the lowest number of risk estimates reported (mean=79.6). The proportion of articles that assessed doseresponse relationships also differed: the proportion of articles that assessed the risk of occupational cancer among both men and women (43.6\%) and men only (41.9\%) were similar, and lower for women only (34.6\%). These results suggest that studies including men and women and men only present more detailed analyses than studies of women only.

\section{Cancers}


Disparities in the inclusion of women in studies of occupational cancer are present in non-sex-specific cancers. In studies of respiratory cancers, which affect both men and women, men were included $95.2 \%$ of the time and women were included $43.2 \%$ of the time (Table II). Similarly, men were included in $94.1 \%$ of studies of digestive cancers, whereas women were included in only $49.4 \%$. There were similar disparities for other cancers, except for breast.

\section{Occupations}

The occupations evaluated by gender composition of the study were similar. The most common occupations evaluated in articles assessing both men and women were production; construction and extraction; transportation and material moving; farming, fishing and forestry; and office and administrative. The most common occupations evaluated in articles assessing cancer risk among men were production; construction and extraction; transportation and material moving; farming, fishing and forestry; and installation, maintenance and repair. The most common occupations evaluated in articles that included women were production; construction and extraction; farming, fishing and forestry; transportation and material moving; and office and administrative.

Several types of occupations were more likely to include men than women (Table III). The largest disparities were in areas such as construction and extraction; installation, maintenance and repair; production; transportation and material moving; and military specific occupations. However, some occupations were more likely to include women, such as community and social services; legal; healthcare practitioners; and healthcare support workers. 


\section{DISCUSSION}

From 1991-2009, there was a substantial increase in the number of epidemiological articles that assessed the risk of cancer related to an occupation, industry or workplace exposure among women. Although the articles that examined risk among women only remained around $10 \%$ of the total through the entire period, the proportion of studies that included any women rose from $39 \%$ to $62 \%$. Because of methodological differences including the lack of distinction between racial or ethnic groups in this review and the additional journals reviewed, these results are not directly comparable to those reported by Zahm and colleagues in 1994. But, these results do suggest inclusion of women in studies of occupational cancer showed an increase of $30-40 \%$ from the 1970s through the early 1990s (Zahm et al. 1994). The reason for the increase in articles including women is not well understood. However, there were several conferences and dedicated journal issues published during this time period that may have contributed (Gunnarsdottir et al. 1999; Kogevinas and Zahm 2003; Pottern et al. 1994). In addition, during the same time period, organizations such as the National Institutes of Health were making an effort to ensure women were not excluded from epidemiologic studies without a good scientific reason.

A limitation of this review is the sole inclusion of English language journals. It is unknown whether the gender balance over time would be different for non-English language articles.

The cancers most commonly assessed in the articles included in this review correspond with those frequently associated with occupational factors. Articles including men evaluated most of the major cancer sites. Among women, except for breast cancer, specific sites were included in only about 50 to 60 percent of the papers. The percentages of the papers including the various cancer sites in papers focusing on men or women only were considerably smaller than papers than included both genders. Lymphoma was among the top five in articles including men, men only or men and women, and leukemia was among the top five in articles including men, women or men and women. In articles that examined a single gender, sex-specific cancers were among the most commonly assessed.

Despite increases in the proportion of articles reporting on the risk of occupational cancer among women, it appears that disparities remain in terms of the depth of analysis. Articles 
reporting on women only had fewer risk estimates than articles reporting on men and women, or men only, and were less likely to report on dose-response relationships. This could be because of smaller numbers of women in the study, but may also indicate that including sufficient numbers of women for analysis was not a high priority in the study design. As discussed above, sometimes methodological adjustments need to be made when studying women such as increasing the sample sizes due to lower exposure rates, utilizing gender-specific exposure assessment techniques, and considering sex- and gender-specific confounders (Arbuckle 2006; Kennedy and Koehoorn 2003; Blair et al. 1999).

This analysis suggests there have been considerable improvements in the inclusion of women in articles assessing occupational cancer over the past two decades. This could be due to the increased workforce participation of women in some industries of interest, an increase in studies specifically aimed at women or women's cancers, along with an awareness of the need for such information on women to make sound societal decisions. Despite gains, attention needs to be paid to ensure that analyses on women are at the same level of depth as those for men. 


\section{ACKNOWLEDGEMENTS}

The authors would like to thank Victoria Arrandale, Daniel Bukvic and Marina Stegne for their contributions to the data collection process, and Desre Kramer for editorial suggestions.

\section{FUNDING}

This project was internally funded by the Occupational Cancer Research Centre in Toronto, Canada. 


\section{REFERENCES}

Arbuckle TE. 2006. Are there sex and gender differences in acute exposure to chemicals in the same setting? Environ Res 101 (2): 195-204.

Blair A, Zahm SH, Silverman D. 1999. Occupational cancer among women: research status and methodologic considerations. Am J Ind Med 36 (1): 6-17.

Friesen MC, Zahm SH, Ward MH, Silverman DT. 2012. Occupation and cancer. In Women and health, edited by Goldman MB, Troisi R, and Rexrode K. Second ed., 629-645. San Diego: Academic Press/Elsevier.

Gunnarsdottir HK, Kjaerheim K, Boffetta P, Rafnsson V, Zahm SH. 1999. Women's health: occupation, cancer, and reproduction: a conference overview. Am J Ind Med 36 (1): 1-5.

Kennedy SM, Koehoorn M. 2003. Exposure assessment in epidemiology: does gender matter? Am J Ind Med 44 (6): 576-583.

Kogevinas M, Zahm SH. 2003. Introduction: epidemiologic research on occupational health in women. Am J Ind Med 44 (6): 563-564.

Locke SJ, Colt JS, Stewart PA,Armenti KR, Baris D, Blair A, Cerhan JR, Chow W-H, Cozen W, Davis F, De Roos AJ, Hartge P, Karagas MR, Johnson A, Purdue MP, Rothman N, Kendra Schwartz K, Schwenn M, Severson R, Silverman DT, Friesen MC. 2013. Identifying gender differences in reported occupational information from three US population-based case-control studies. Occup Environ Med 2014doi:10.1136/oemed-2013-101801.

Messing K and Mergler D. 2006. Introduction: women's occupational and environmental health. Environ Res 101 (2): 147-148.

Messing K, Punnett L, Bond M, Alexanderson K, Pyle J, Zahm SH, Wegman D, Stock SR, de Grosbois S. 2003. Be the fairest of them all: challenges and recommendations for the treatment of gender in occupational health research. Am J Ind Med 43 (6): 618-629.

Niedhammer I, Saurel-Cubizolles MJ, Piciotti M, Bonenfant S. 2000. How is sex considered in recent epidemiological publications on occupational risks? Occ Environ Med 57 (8): 521-527.

Pottern LM, Zahm SH, Sieber SS, Schneider IJ, LaRosa JH, Brown DP, Collman GW, Fingerhut MA, Waters MA. 1994. Occupational cancer among women: a conference overview. J Occ Med $36(8): 809-13$.

SAS Institute Inc. Base SAS® 9.3. 2011. Cary, NC: SAS Institute Inc.

United States Bureau of Labor Statistics. 2010. Standard occupational classification. Availble at: http://www.bls.gov/soc/

United States Department of Labor. 2014. Labor Force Participation Rates by Sex and Race or Hispanic Ethnicity, 1972-2012. Available at: http://www.dol.gov/wb/stats/LForce_Race_Hispanic_Ethnicity_72_12_txt.htm

Zahm SH, Fraumeni JF. 1995. Racial, ethnic and gender variations in cancer risk: considerations for future epidemiologic research. Environ Health Perspect 103 Suppl 8: 283-6. 
Zahm SH, Pottern LM, Lewis DR, Ward MH, White DW. 1994. Inclusion of Women and Minorities in Occupational Cancer Epidemiologic Research. J Occ Med 36 (8): 842-7.

Zahm SH, Blair A. 2003. Occupational cancer among women: where have we been and where are we going? Am J Ind Med 44 (6): 565-575. 


\section{FIGURE LEGEND}

Figure 1: Articles assessing the relationship between an occupational factor and cancer, by publication period and gender inclusion

1991-1995

$1996-2000$

2001-2005

2006-2009 